\title{
Delphi-AHP and Weighted Index Overlay-GIS Approaches for Industrial Site Selection Case Study: Large Extractive Industrial Units in Iran
}

\author{
Mohammadreza KAMALI', Ali Asghar ALESHEIKH², Seyedeh Azadeh ALAVI BORAZJANI3, \\ Akram JAHANSHAHI4, Zahra KHODAPARAST5, Mohammadreza KHALAJ1 \\ ${ }^{1}$ University of Aveiro, Department of Environment and Planning, Aveiro, PORTUGAL \\ ${ }^{2}$ Khajeh Nasir Toosi University of Technology, Department of Geospatial Information Systems, Tehran, IRAN \\ 3 University of Aveiro, Department of Environment and Planning, and Department of Mechanical Engineering, Aveiro, PORTUGAL \\ ${ }_{4}$ University of Aveiro, Department of Economics, Management, Industrial Engineering and Tourism, and Department of Mechanical \\ Engineering, Aveiro, PORTUGAL \\ 5 University of Aveiro, Department of Biology, Aveiro, PORTUGAL \\ E-mail: kamali@ua.pt, alesheikh@kntu.ac.ir, saab@ua.pt, jahanshahi@ua.pt, khodaparast@ua.pt, khalaj@ua.pt \\ DOI: 10.24193/JSSP.2017.2.03 \\ https://doi.org/10.24193/JSSP.2017.2.03
}

K e y w o r d s: multi-criteria decision-making, industrial site selection, Weighted Index Overlay, GIS

\begin{abstract}
A B S T R A C T
Evaluation of suitable sites for locating a large extractive industrial unit can be considered as a multi-criteria decision-making problem. Such a complicated process often requires considering the conflicting tangible and intangible criteria. This paper aims to propose a combination of a Delphi-analytical hierarchy process approach and geographical information system methodology in order to find the optimum sites for the large extractive industrial units in Iran. To this end, the most influential criteria and sub-criteria were firstly identified and weighted using Delphi method and analytical hierarchy process, respectively. Then, in order to specify the suitable sites for establishing a large extractive industrial unit in Iran, the results obtained from analytical hierarchy process were integrated into the weighted index overlay method in the geographical information system environment. The combination of Delphi and analytical hierarchy process with geographical information system revealed an acceptable performance for the identification and weighting of the effective criteria and the selection of the most suitable large extractive industrial unit sites in Iran.
\end{abstract}

\section{INTRODUCTION}

Site selection, as a key principle of spatial planning, plays an immensely important role towards the success or failure of the establishment of industrial activities. Indeed, the most suitable location for a large industrial unit is defined as a place in which industrial activities can be settled with a minimal consumption of primary resources (manpower, equipment, material, cost, and time) while being logistically and economically feasible, providing enough assurance for further development [1]. Therefore, a number of probable alternatives as well as multifold and often conflicting evaluation criteria such as economic, environmental, technical, social, political etc. must be considered when determining the land suitability for such industries [2]. In this regard, methods based on the multi-criteria decision making (MCDM), which are mainly relying on the concepts of accurate measurements and crisp evaluation, can be used to assist the decision makers by providing the appropriate candidates for the site selection of the large extractive industrial units (LEIUs) (units with 100,000 tones production per year) [3], [4]. 
One of the most widely applied MCDM techniques is the analytical hierarchy process (AHP) [5]. This method was firstly developed by Saaty (1980) to weight a branch of qualitative and quantitative variables, making a unit scale for prioritization [6]. It can provide a systematic approach for weighting and evaluating the impacts of various parameters on the selection of a suitable site for LEIUs [7]. By using AHP, the decision-making process can be divided into several hierarchical levels so that a decision can be made based on the knowledge and experience of relevant experts through a pairwise comparison at each level [8]. Herein, the Delphi technique defined as "a method for structuring the group communication process for dealing with a complex problem" can be used for extracting and screening the influential criteria for finding the preferable LEIU sites, through computing the "degree of importance" and the "percentage of importance" values [9], [10]. This method has the ability to overcome the shortcomings of the common methods such as brainstorming (in which group collective thinking may affect the final results) by providing the chance for experts to reply anonymously [11].

In recent years, integration of the MCDM methods (such as AHP) with geographical information system (GIS) has provided a powerful decision support system (DSS) to be used for the spatial planning purposes [12]. GIS is a computer-based mapping and information integrating process with the ability of data layers management to make the appropriate decisions by combining the geological, geographical, environmental, and other kinds of information layers [12], [13]. Accordingly, many studies have been conducted emphasizing the adoption of Delphi, AHP or a combination of these methods with GIS in order to analyze and model the spatial suitability [11], [12], [13], [14], [15], [16], [17], [18], [19], [20]. However, there have been a few studies assessing the land suitability for industrial units by using such integrated approach [2], [3]. Therefore, the aims of the present manuscript are: (i) the application of Delphi and AHP methods for identifying and weighing the most influential criteria and sub-criteria involving in the selection of the appropriate site for large-scale industries in Iran; and (ii) to specify the most suitable location for such industries by using the weighted index overlay (WIO) method in GIS environment.

\section{METHODOLOGY}

The selection and screening process of the criteria and sub-criteria, and the weighting process was carried out using Delphi and AHP methods [3]. To this end, 10 experts with a sufficient technical and scientific knowledge in the environmental field as well as industrial activities were asked to state their opinion on 100 the importance of the main criteria and sub-criteria in the Delphi questionnaire by one of the five degrees of importance (i.e., 1, 3, 5, 7 and 9). Then, for each criterion, two statistical elements consisting of the percentage of importance (PI) and degree of importance (DI) were calculated to provide a possibility for the selection of criteria based on the plotted importance graph (IG). Each criterion with a PI or DI less than the median value of IG must be removed from the criteria selection [24]. The mathematical calculations of PI and DI are given by Eqs. 1 and 2.

$$
\begin{aligned}
& P I=\frac{\sum Z_{i}}{A} \times 100 \\
& D I=\frac{\sum X_{i \times n}}{N}
\end{aligned}
$$

where: $A$ represents the maximum weighted value attainable by Eq. 3, and also $Z_{i}$ is the weighted value of each criterion which can be calculated based on Eq. 4. In this equation, the moderated values $\left(Y_{i}\right)$ can be computed by multiplying the initial values by the moderated coefficient $\left(X_{i}\right)$ obtained through Eq. 5, and $n_{i}$ shows the number of experts who evaluated the importance of each criterion by one of the values of 1,3 , 5,7 and 9 .

$$
\begin{aligned}
& A=N \times W \\
& Z_{i}=Y_{i} \times n_{i} \\
& X_{i}=\frac{10}{\left(\sum(1+3+5+7+9)\right.}
\end{aligned}
$$

In the next step, for determining the relative weights of the criteria and sub-criteria in AHP method, the referred experts performed their pairwise comparisons with Saaty's nine-point scale [25], and the judgment matrices were extracted (Eq. 6).

$M=\left[\begin{array}{cccc}1 & a 12 & \cdots & a 1 n \\ 1 / a 12 & 1 & \cdots & a 2 n \\ \vdots & \vdots & \ddots & \vdots \\ 1 / a 1 n & 1 / a 2 n & \cdots & 1\end{array}\right]$

In this matrix, $a_{i j}=1 / a_{j i}$. Thus, when $i=j$, it can be concluded that $a_{i j}=1$. The normalization of the decision matrix was performed in such a way that each value was divided by the sum of values existing in each column and ultimately by calculating the row values average, the weights were obtained. To ensure the consistency within the pairwise comparison matrix, a consistency index $(C I)$ was defined according to Eq. 7 . 
$C I=\frac{\lambda \max -n}{n-1}$

where: $\lambda_{\max }$ refers to the largest eigenvalue of decision matrix, and $n$ is the number of criteria. Accordingly, the final consistency ratio $(C R)$ was obtained by Eq. 8 to measure the degree of $C I$.

$$
C R=\frac{C I}{R I}
$$

In this equation, $R I$ is the random consistency index. Its value is relevant to the dimension of the matrix developed by Saaty [25]. If $C R$ exceeded 0.1, the evaluation procedure must be repeated to improve the consistency. Finally, weighted index overlay (WIO) method was applied in order to prioritization of the suitable sites for establishing a LEIU in the scope of this study, Nezam Abad Tungsten mine (Iran) (Fig. 1).

The equation of weighted index overlay is expressed as follows (Eq. 9) [13]:

$$
S=\frac{\sum_{i}^{n} W_{i} B_{i}}{\sum_{i}^{n} W_{i}}
$$

In this equation, $B_{i}(\mathrm{i}=1,2, \ldots, \mathrm{n})$ refers to the binary evidential map and $W_{i}$ is the weight of each binary evidential map (see Table 1 ).

The value of each location in the output combined map $(S)$ reflects the integrated characteristics of the information layers and the cumulative importance of them. Compared to Boolean logic modelling, WIO can represent more than 2 classes for the eligibility of each location (pixel) in the final map [26]. In this study, Arc GIS (9.3) was utilized in order to integrate the information layers.

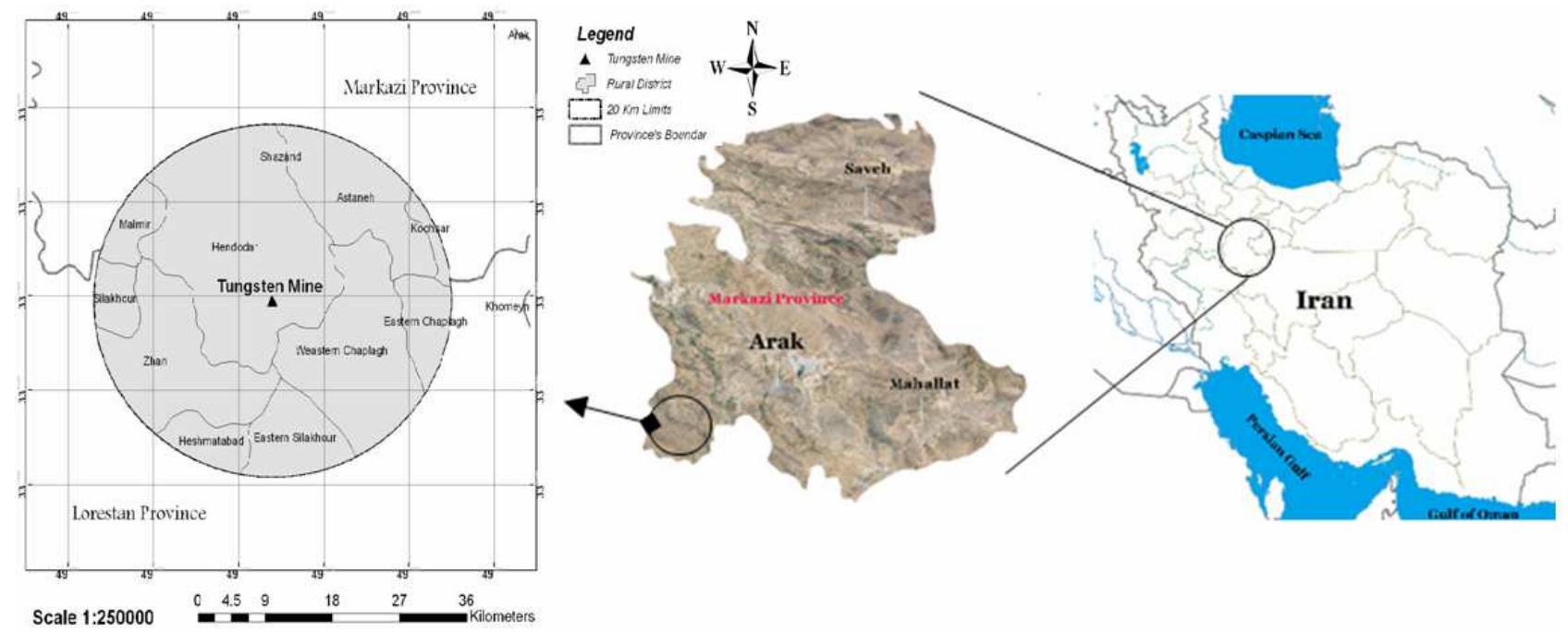

Fig. 1. Study area (Nezam Abad Tungsten mine) located in Markazi Province, Iran.

\section{RESULTS AND DISCUSSION}

Selection and screening the criteria and subcriteria were performed according to the Delphi method. The results of the screening process presented in Table 1 and Fig. 2, indicated that all sub-criteria are eligible to be used for the selection of the LEIUs.

The relevant weights of the sub-criteria, calculated based on the AHP methodology are also included in Table 1 . The weighted information layers, achieved from the screening and weighting the criteria and sub-criteria (Table 1) were utilized to construct the WIO formula. For this, the value of each informative layer was multiplied by the allocated weight [13]. This way, the value of the main layer(s) increases, according to the weights assigned by the experts in the field. Finally, the sum of the values was divided by 100 (as the total coefficient).

Eq. 10 presents the formula of the WIO methodology in this study based on the results achieved.

$$
L W=\frac{+(\mathrm{RM} \times 15.93)+(\mathrm{W} \times 3.58)+(\mathrm{P} \times 11.85)+(\mathrm{GS} \times 11.96)+(\mathrm{L} \times 5.12)+(E \times 7.01)}{100}
$$

Through analyzing the relevant informative layers contributing to the screened sub-criteria according to the Eq. 10, the areas with the potential for the establishment of a large extractive industrial unit in Iran were categorized. Fig. 3 represents these categories reflecting their suitability identified using WIO 
methodology in GIS. In this figure, the limitations such as distance to the local faults and also the distance to the local environmental vulnerable sites (national parks or protected areas) are excluded according to the legal considerations [27], obliging the prevention of industrial activities in such areas. As it is evident from Fig. 3 and 4, the most suitable areas are concentrated in the central part of the study area. According to the results, the RM factor was identified as the most important parameter for establishment of LEIUs.

Table 1. Main criteria and sub-criteria for site selection of the large extractive industrial units in Iran. The relative weights of the criteria and sub-criteria and the acceptable ranges are also provided.

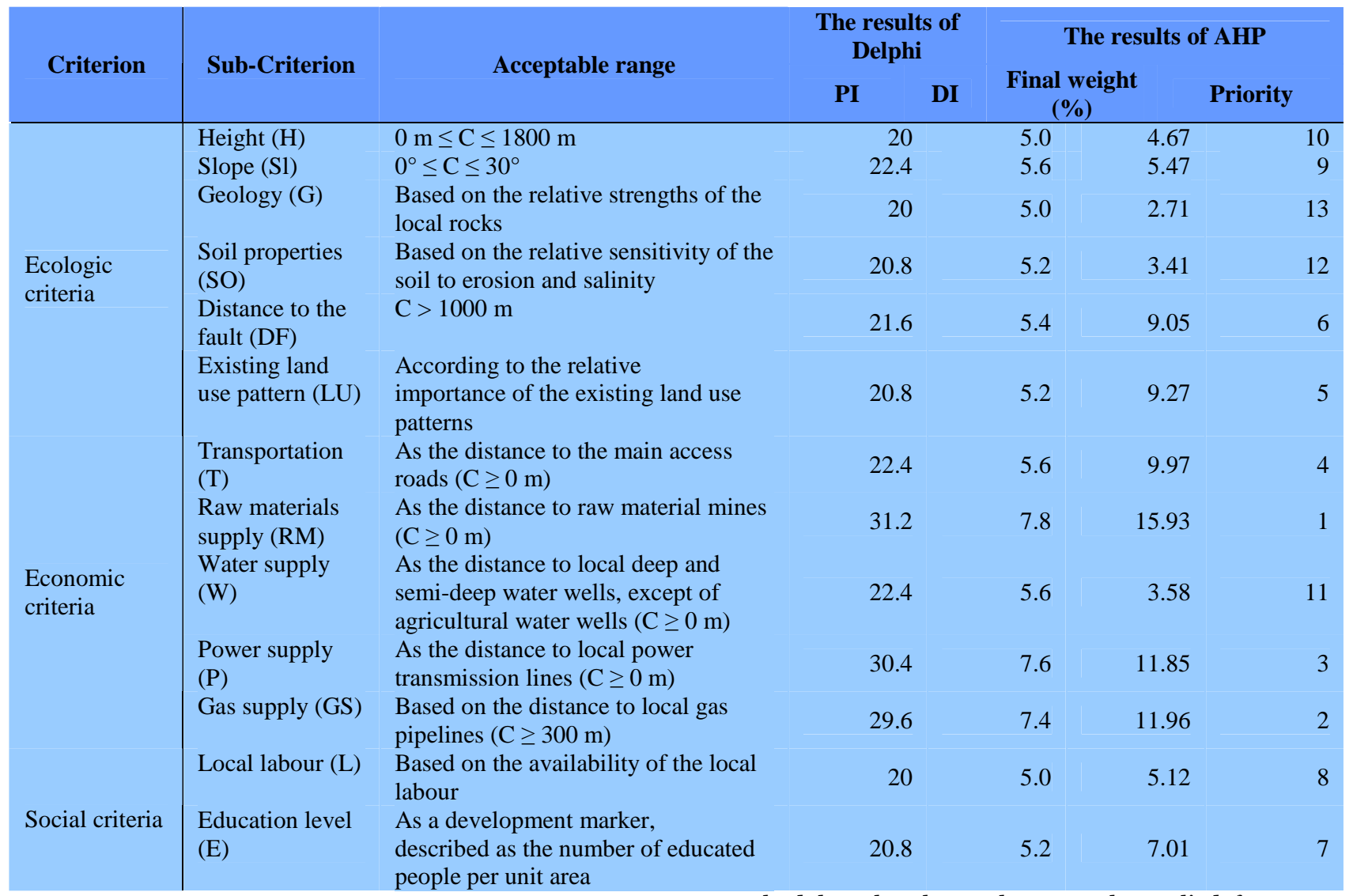

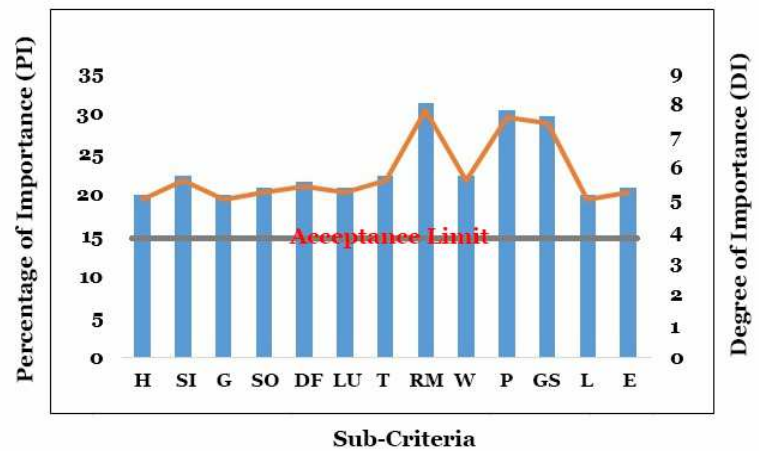

Fig. 2. The graph of the importance and acceptance limit of the sub-criteria according to the results achieved from Delphi screening method.

The results of this study can represent the efficiency of the WIO method to transfer the knowledge of the experts on the relative importance of the influencing criteria to the actual land use decisionmaking process in order to select the most appropriate sites for establishing the desired activities. This methodology has been also recently applied for some specific applications such as groundwater risk assessment [28], geothermal potential assessment [13], municipal solid waste land filling [29] etc. However, the application of WIO methodology for industrial site selection has not been well reported yet. WIO is more helpful and flexible compared to the conventional models such as Boolean, especially for the site selection applications, which require providing a range of decision possibilities. This method is relatively fast relying on less detailed information, which is important when considering the cost-effectiveness of such studies. Although other methods such as fuzzy logic can provide very accurate results [13], [30], they need detailed informative layers, which can make these methods more complicated than WIO.

Comparing the results of this study to our previous study using fuzzy logic (weighted linear combination method), the results are very similar to each other proving this fact that the WIO is also a reliable method to provide materials for the decision makers [3]. As shown in Fig. 4, a site with an appropriate area (83 
hectares) having a relatively high degree of suitability has been suggested for the establishment of a large extractive industrial unit in Iran. It is evident that after decision-making process based on the results raised from this study, it would be necessary to carry out specific local environmental studies such as environmental impact assessment to establish an ecofriendly industry, which can ensure the economic benefits in a long-time life cycle [31], [32]. Sustainable designs are also required to control the pollutants released to the environment to ensure that the industry is developed completely eco-friendly [33], [34].

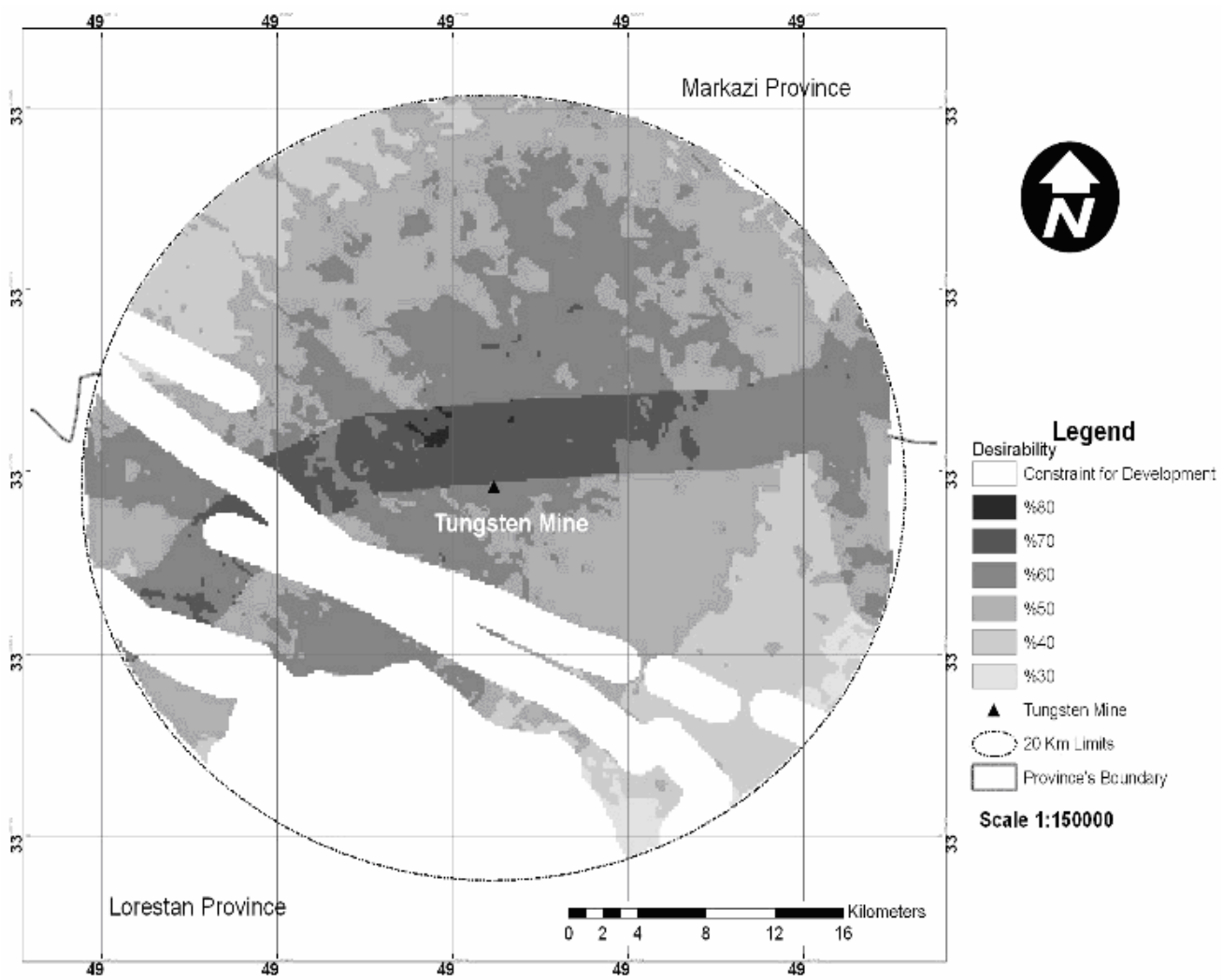

Fig. 3. The categories of the areas for the establishment of a large extractive industrial unit in Iran, Nezam Abad, Markazi Province, Iran.

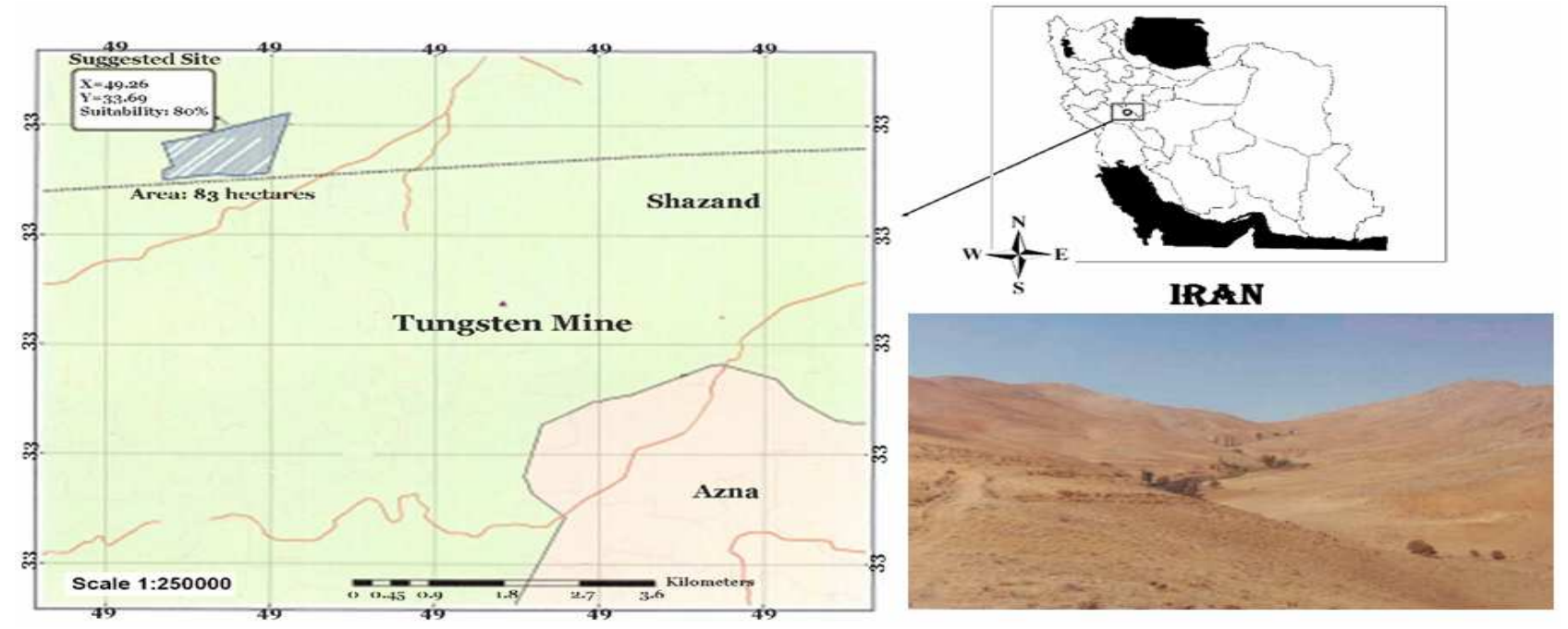

Fig. 4. The suggested site for establishing a large extractive industrial unit in Iran (Nezam Abad Tungsten mine) located in Markazi Province, Iran.

\section{CONCLUSION}

Given the ability of GIS in the combination of environmental (ecological, social and economical) informative layers based on the mathematical methods together with experts' ideas, site selection of the highly polluting industries can be facilitated. In this study, we employed a combination of Delphi-AHP and WIO integration model in GIS. Thirteen sub-criteria were screened using the Delphi method and their relative weights were identified using the AHP methodology. 
The weighted information layers of the study area were used for selection of the best sites for the establishment of a LEIU in Iran using WIO integration model. Based on the results achieved in this study, WIO method can be considered as a good candidate with relatively high levels of accuracy and relatively low cost as well as low time requirements for such applications. Hence, it can be useful for future applications in order to establish highly polluting industrial activities, especially when the number of informative layers is not adequate to perform more complicated methodologies.

\section{REFERENCES}

[1] Kumar, S., Bansal, V. K. (2016), A GIS-based methodology for safe site selection of a building in a hilly region, In: Front. Archit. Res., vol. 5, issue 1, pp. 39-51.

[2] Rikalovic A., Cosic, I., Lazarevic, D. (2014), GIS Based Multi-criteria Analysis for Industrial Site Selection, In: Procedia Eng., vol. 69, pp. 1054-1063.

[3] Kamali, M., Alesheikh, A. A., Khodaparast, Z., Hosseinniakani, S. M., Alavi Borazjani, S. A. (2015), Application of Delphi-AHP and Fuzzy-GIS Approaches for Site Selection of Large Extractive Industrial Units in Iran, In: J. Settlements Spat. Plan., vol. 6, no. 1, pp. 9-17.

[4] Önüt, S., Efendigi, T. L, Soner Kara S. (2010), A combined fuzzy MCDM approach for selecting shopping center site: An example from Istanbul, Turkey, In: Expert Syst. Appl., vol. 37, no. 3, pp. 1973-1980.

[5] Aalianvari, A., Katibeh, H., Sharifzadeh, M. (2012), Application of fuzzy Delphi AHP method for the estimation and classification of Ghomrud tunnel from groundwater flow hazard, In: Arab. J. Geosci., vol. 5, pp. 275-284.

[6] Saaty, T. L. (1980), The Analytic Hierarchy Process, McGraw-Hill, New York, USA.

[7] Rahmati, O., Haghizadeh, A., Stefanidis, S. (2016), Assessing the Accuracy of GIS-Based Analytical Hierarchy Process for Watershed Prioritization; Gorganrood River Basin, Iran, In: Water Resour. Manag., vol. 30, pp. 1131-1150.

[8] Kaya, B. Y., Dagdeviren, M. (2016), Selecting Occupational Safety Equipment by MCDM, In: Hum. Factors Ergon. Manuf. Serv. Ind. 26, vol. 26, no. 2, pp. 224-242.

[9] Delbari, S. A., Ng, S. I., Aziz, Y. A., Ho, J. A. (2016), An investigation of key competitiveness indicators and drivers of full- service airlines using Delphi and AHP techniques, In: J. Air Transp. Manag., vol. 52, pp. 23-34.

[10] Mousavi, S. M., Tavakkoli-Moghaddam, R., Heydar, M., Ebrahimnejad S. (2013), MultiCriteria Decision Making for Plant Location Selection : An Integrated Delphi - AHP - PROMETHEE
Methodology, In: Arab. J. Sci. Eng., vol. 38, pp. 12551268.

[11] Kim, M., Jang, Y., Lee, S. (2013), Application of Delphi-AHP methods to select the priorities of WEEE for recycling in a waste management decision-making tool, In: J. Environ. Manage., vol. 128, pp. 941-948.

[12] Kazemi, H., Sadeghi, S., Akinci, H. (2016), Developing a land evaluation model for faba bean cultivation using geographic information system and multi-criteria analysis (A case study: Gonbad-Kavous region, Iran ), In: Ecol. Indic., vol. 63, pp. 37-47, 2016. [13] Sadeghi, B., Khalajmasoumi, M. (2014), A futuristic review for evaluation of geothermal potentials using fuzzy logic and binary index overlay in GIS environment, In: Renew. Sustain. Energy Rev., vol. 43, pp. 818-831.

[14] Mousavi, S. H., Danehkar, A., Shokri, M. R., Poorbagher, H., Azhdari, D. (2015), Site selection for artificial reefs using a new combine Multi-Criteria Decision-Making ( $M C D M$ ) tools for coral reefs in the Kish Island e Persian Gulf, In: Ocean Coast. Manag., vol. 111, pp. 92-102.

[15] Capilla, J. A. J., Carrión, J. A., AlamedaHernandez, E. (2016), Optimal site selection for upper reservoirs in pump-back systems, using geographical information systems and multicriteria analysis, In: Renew. Energy J., vol. 86, pp. 429-440.

[16] Hasanzadeh, M., Danehkar, A., Azizi, M. (2013), The application of Analytical Network Process to environmental prioritizing criteria for coastal oil jetties site selection in Persian Gulf coasts (Iran), In: Ocean Coast. Manag., vol. 73 (March), pp. 136-144.

[17] Sánchez-Lozano, J. M., Teruel-Solano, J., Soto-Elvira, P. L., García-Cascales, M. S. (2013), Geographical Information Systems ( GIS ) and MultiCriteria Decision Making ( $M C D M$ ) methods for the evaluation of solar farms locations: Case study in south-eastern Spain, In: Renew. Sustain. Energy Rev., vol. 24, pp. 544-556.

[18] Uyan, M. (2013), GIS-based solar farms site selection using analytic hierarchy process (AHP) in Karapinar region, Konya/Turkey, In: Renew. Sustain. Energy Rev., vol. 28 (Dec), pp. 11-17.

[19] Potić, I., Golić, R., Joksimović, T. (2016), Analysis of insolation potential of Knjaževac Municipality (Serbia) using multi-criteria approach, In: Renew. Sustain. Energy Rev., vol. 56, pp. 235-245.

[20] Noorollahi, Y., Yousefi, H., Mohammadi, M. (2016), Multi-criteria decision support system for wind farm site selection using GIS, Sustain. Energy Technol. Assessments, vol. 13, pp. 38-50.

[21] Aydi, A., Abichou, T., Nasr, I. H., Louati, M., Zairi, M. (2016), Assessment of land suitability for olive mill wastewater disposal site selection by integrating fuzzy logic , AHP, and WLC in a GIS, In: Environ. Monit. Assess., vol. 188, p. 59. 
[22] El Baba, M., Kayastha, P., De Smedt, F. (2015), Landfill site selection using multi-criteria evaluation in the GIS interface : a case study from the Gaza Strip., Palestine, In: Arab. J. Geosci., vol. 8, pp. 7499-7513.

[23] Jozi, S. A., Ebadzadeh, F. (2014), Application of Multi-Criteria Decision-Making in Land Evaluation of Agricultural Land Use, In: J. Indian Soc. Remote Sens., vol. 42, no. 2, pp. 363-371.

[24] Sepehr, M., Fatemi, S.M.R., Danehkar, A., Moradi, A. M. (2017), Application of Delphi method in site selection of desalination plants, In: Glob. J. Environ. Sci. Manag., vol. 3, no. 1, pp. 89-102.

[25] Saaty, T. L. (1982), The Analytical Hierarchy Process for Decision in a Complex World, Belmont, CA Lifetime Learn. Publ., USA.

[26] Moghaddam, M. K., Samadzadegan, F., Noorollahi, Y., Sharifi, M. A., Itoi, R. (2014), Spatial analysis and multi-criteria decision making for regional-scale geothermal favorability map, In: Geothermics, vol. 50, pp. 189-201.

[27] Iran ministers council (2011), Regulation 59309: The rules and criteria for establishment of industrial and manufacturing units and activities.

[28] Shrestha, S., Kafle, R., Pandey, V. P. (2017), Evaluation of index-overlay methods for groundwater vulnerability and risk assessment in Kathmandu Valley, Nepal, In: Sci. Total Environ., vol. 575, pp. 779790.

[29] Arkoc, O. (2013), Municipal solid waste landfill site selection using geographical information systems: a case study from Corlu, Turkey, In: Arab. J. Geosci., vol. 7, no. 11, pp. 4975-4985.

[30] Du, X., Zhou, K., Cui, Y., Wang, J., Zhang, N., Sun, W. (2016), Application of fuzzy analytical hierarchy process $(A H P)$ and prediction-area $(P-A)$ plot for mineral prospectivity mapping: a case study from the Dananhu metallogenic belt, Xinjiang, NW China, In: Arab. J. Geosci., vol. 9, no. 4, DOI: https://doi.org/10.1007/s12517-016-2316-y.

[31] Korol, J., Burchart-Korol, D., Pichlak, M. (2016), Expansion of environmental impact assessment for eco-efficiency evaluation of biocomposites for industrial application, In: J. Clean. Prod., vol. 113, pp. 144-152.

[32] Parajuli, I., Lee, H. (2017), Study on integration techniques for Environmental Impact Assessment of different media based standard industrial classification: A case study of South Korea, In: J. Clean. Prod., vol. 151, pp. 643-651.

[33] Kamali, M., Gomes, A. P. D., Khodaparas Z., Seifi, T. (2016), Review on recent advances in environmental remediation and related toxicity of engineered nanoparticles, Environ. Eng. Manag. J., vol. 15, pp. 923-934.

[34] Kamali, M., Costa, M. E., Capela, I. (2017), Nitrate Removal and Nitrogen Sequestration from Polluted Waters Using Zero Valent Iron Nanoparticles Synthesized under Ultrasonic Irradiation, In: Advanced Materials for Wastewater Treatment, Hoboken, NJ, USA: John Wiley \& Sons, Inc., pp. 479505 . 